\title{
Quality of life in patients with chronic thromboembolic pulmonary hypertension
}

\author{
Stephen C. Mathai ${ }^{1}$, Hossein-Ardeschir Ghofrani ${ }^{2}$, Eckhard Mayer ${ }^{3}$, \\ Joanna Pepke-Zaba ${ }^{4}$, Sylvia Nikkho ${ }^{5}$ and Gérald Simonneau ${ }^{6}$
}

Affiliations: ${ }^{1}$ Division of Pulmonary and Critical Care Medicine, Johns Hopkins University School of Medicine, Baltimore, MD, USA. 'University of Giessen and Marburg Lung Center, Giessen, Germany, member of the German Center for Lung Research (DZL). ${ }^{3}$ Kerckhoff Heart and Lung Center, Bad Nauheim, Germany. ${ }^{4}$ Pulmonary Vascular Disease Unit, Papworth Hospital, Cambridge, UK. ${ }^{5}$ Global Clinical Development, Bayer Pharma AG, Berlin, Germany. ${ }^{6}$ Assistance Publique-Hôpitaux de Paris, Service de Pneumologie, Hôpital Bicêtre, Université Paris-Sud, Laboratoire d'Excellence en Recherche sur le Médicament et Innovation Thérapeutique, and INSERM Unité 999, Le Kremlin-Bicêtre, France.

Correspondence: Stephen C. Mathai, Johns Hopkins University School of Medicine, Division of Pulmonary and Critical Care Medicine, 1830 E. Monument Street, Room 540, Baltimore, MD 21205, USA.

E-mail: smathai4djhmi.edu

ABSTRACT Patients with chronic thromboembolic pulmonary hypertension (CTEPH) experience debilitating symptoms that have a negative impact on their quality of life (QoL) in terms of physical capability, psychological wellbeing and social relationships. The use of QoL measurement tools is important in the assessment of treatment efficacy and in guiding treatment decisions. However, despite the importance of QoL, particularly to the patient, it remains under-reported in clinical studies of CTEPH therapy. CTEPH is unique in pulmonary hypertension in that it is potentially curable by surgery; however, a proportion of patients either have residual $\mathrm{PH}$ following surgery or are not operable. Although some patients with CTEPH have been treated off-label with pulmonary arterial hypertension-specific therapies, there have been few randomised controlled trials of these therapies in patients with CTEPH. Moreover, in these trials QoL outcomes are variably assessed, and there is little consistency in the tools used. Here we review the assessment of QoL in patients with CTEPH and the tools that have been used. We also discuss the effect of surgical intervention and medical therapies on QoL. We conclude that further studies of QoL in patients with CTEPH are needed to further validate the optimal QoL tools.

@ERSpublications

HRQoL is rarely measured in CTEPH trials: further studies are needed as well as validation of appropriate HRQoL tools http://ow.ly/ZrkL1

Received: Oct 012015 | Accepted after revision: March 062016 | First published online: April 132016

Support statement: This study was supported by Bayer Pharma AG. Funding information for this article has been deposited with FundRef.

Conflict of interest: Disclosures can be found alongside the online version of this article at erj.ersjournals.com

Copyright OERS 2016. ERJ Open articles are open access and distributed under the terms of the Creative Commons Attribution Non-Commercial Licence 4.0. 


\section{Introduction}

Chronic thromboembolic pulmonary hypertension (CTEPH) is a rare and chronic disease, characterised by the presence of residual organised thrombi in the pulmonary vasculature [1], leading to increased pulmonary vascular resistance (PVR), progressive pulmonary hypertension $(\mathrm{PH})$ and eventually, right ventricular failure $[2,3]$. The symptoms of CTEPH include dyspnoea, fatigue, chest pain, reduced exercise capacity, weight loss, oedema, weakness, palpitations and syncope. Historical data suggest that 5-year survival rates are $\sim 30 \%$ in untreated patients [4]. The physically and psychologically disabling nature of CTEPH can severely impact patients' relationships with family and friends, their ability to work and exercise, and their financial security [5].

Pulmonary endarterectomy (PEA) is the gold standard for CTEPH treatment as it is potentially curative $[6,7]$. However, 20-40\% of patients with CTEPH have inoperable disease [8] and of those who undergo surgery, 17-35\% will have residual CTEPH [9-12]. Such patients are candidates for pharmacotherapy and until recently, were often treated off-label with pulmonary arterial hypertension (PAH)-specific therapies due to a lack of approved alternatives $[9,13,14]$. Riociguat, a soluble guanylate cyclase stimulator, is the first drug to be approved for the treatment of patients with inoperable or persistent/recurrent CTEPH [15-18].

Quality of life (QoL) measures are part of the broader category of health status measures collectively referred to as patient-reported outcomes (PROs). PROs elicit information directly from the patient regarding any aspect of their health or care. QoL tools assess, to varying degrees, the patient's subjective perception of the impact of their disease and its treatment on their daily life, on physical, psychological and social functioning, and on general wellbeing. Thus, measurement of QoL in patients with CTEPH provides an important insight into the broader impact of the disease, beyond clinical symptoms and objectively measurable clinical end-points that do not always fully represent the impact of treatment on the patient's daily life. However, QoL is not routinely assessed in clinical practice and is rarely reported as an outcome in clinical trials of CTEPH.

This article will describe the tools used to measure QoL in CTEPH. Further, we will review the QoL data from prior clinical studies of both surgical and medical interventions in CTEPH. Recent advances in the measurement of QoL in CTEPH will also be discussed.

\section{QoL in patients with $\mathrm{PH}$}

QoL measures have been shown to correlate with clinical outcomes typically measured in CTEPH and other forms of $\mathrm{PH}$ such as exercise capacity, haemodynamics, World Health Organization (WHO) functional class (FC), clinical deterioration and survival [19-23]. Although few studies have specifically investigated QoL in patients with CTEPH, several studies have examined QoL in mixed PH populations that included patients with CTEPH and patients with PAH. Compared with the general population, patients with PH have a substantially reduced QoL [22]. This is unsurprising, as patients with PH have to manage the physical burden of the disease, unclear prognosis, high cost of treatment, unemployment and financial uncertainty, and the impact on social relationships. Consequently, psychological disorders such as depression and anxiety are common, and have also been shown to significantly impact QoL in patients with PH $[20,24]$.

Understandably, patients with PH place great importance on their QoL. In a survey carried out by the European Pulmonary Hypertension Association, 455 patients with PAH and their caregivers from five European countries replied to questionnaires regarding the physical, practical, emotional and social impact of PAH, and information needs and provision [25]. The results showed that $56 \%$ of patients reported that PAH had a "significant" impact on their daily life; $85 \%$ said that their work was affected; $73 \%$ had a reduced household income; and 55\% reported feeling isolated, with a major reason being lack of understanding of the disease by family and friends [25]. Furthermore, in an ethnographic study of patients with $\mathrm{PH}$, one of the principal findings was the secrecy that surrounds living with the disease, with many patients admitting to hiding their symptoms and to feelings of isolation and insecurity [5].

\section{QoL measurement tools}

QoL is measured using multidimensional tools that require the patient to report a variety of physical, psychological and social aspects of their daily life. Several different PRO measurement tools have been used in studies of patients with CTEPH, including both generic QoL questionnaires and health-related QoL (HRQoL) questionnaires tailored for patients with $\mathrm{PH}$ or heart failure. These are summarised in table 1.

The Medical Outcomes Study (MOS)/Rand Short Form 36 (SF-36), the shortened derivation of the SF-36 (the SF-12) and the EuroQol-5D (EQ-5D), which comprises the five-dimensional self-reported questionnaire and a self-reported visual analogue scale (EQ-VAS), are generic QoL surveys, all of which are widely used. In patients with CTEPH, the generic SF-36 and SF-12 have been used in clinical trials of 
TABLE 1 Patient-reported outcome (PRO) tools used in studies of patients with chronic thromboembolic pulmonary hypertension (CTEPH)

\begin{tabular}{|c|c|c|c|c|c|c|c|c|}
\hline PRO tool [ref.] & Type & Items & Domains & Scoring & MID" & Validation & Correlations & $\begin{array}{l}\text { Recall } \\
\text { period }\end{array}$ \\
\hline $\begin{array}{l}\text { MOS/Rand } \\
\text { 36-item } \\
\text { Short Form } \\
\text { (SF-36] [26] }\end{array}$ & Generic & 36 & $\begin{array}{l}\text { Physical functioning } \\
\text { Role physical } \\
\text { Bodily pain } \\
\text { General health } \\
\text { Vitality } \\
\text { Social functioning } \\
\text { Role emotional } \\
\text { Mental health }\end{array}$ & $\begin{array}{l}0-100 \text { where } 50 \text { is } \\
\text { equal to the } \\
\text { population norm }\end{array}$ & $\begin{array}{l}\text { In patients with PAH: } \\
\text { Physical } \\
\text { functioning=13 } \\
\text { Role physical=25 } \\
\text { Social functioning=21 } \\
\text { Vitality=15 [27] }\end{array}$ & $\begin{array}{l}\text { Validated by the IQOLA project } \\
\text { in } 15 \text { countries }\end{array}$ & $\begin{array}{l}\text { 6MWD, NYHA FC, } \\
\text { haemodynamics }\end{array}$ & 4 weeks \\
\hline $\begin{array}{l}\text { MOS 12-item } \\
\text { Short Form } \\
\text { (SF-12) [28] }\end{array}$ & Generic & 12 & $\begin{array}{l}\text { Physical functioning } \\
\text { Role physical } \\
\text { Bodily pain } \\
\text { General health } \\
\text { Vitality } \\
\text { Social functioning } \\
\text { Role emotional } \\
\text { Mental health }\end{array}$ & $\begin{array}{l}0-100 \text { where } 50 \text { is } \\
\text { equal to the } \\
\text { population norm }\end{array}$ & $\begin{array}{l}\text { In patients with COPD: } \\
\text { Physical component } \\
\text { score } 3=\text { units, } \\
\text { mental component } \\
\text { score }=3.5 \text { units [29] }\end{array}$ & $\begin{array}{l}\text { Validated by the IQOLA project } \\
\text { in nine countries }\end{array}$ & $\begin{array}{c}\text { Corresponding } \\
\text { scores in the SF-36 }\end{array}$ & 4 weeks \\
\hline $\begin{array}{l}\text { EuroQol-5D } \\
\text { (EQ-5D)/ } \\
\text { EQ-Visual } \\
\text { Analogue Scale } \\
\text { (VAS) [30] }\end{array}$ & Generic & 5 & $\begin{array}{c}\text { Mobility } \\
\text { Self-care } \\
\text { Usual activities } \\
\text { Pain/discomfort } \\
\text { Anxiety/depression }\end{array}$ & $\begin{array}{c}-0.59-1.00, \text { where } \\
1.00=\text { full health } \\
\text { VAS from } 0 \text { (worst } \\
\text { possible health) to } \\
100 \text { (best possible } \\
\text { health) }\end{array}$ & $\begin{array}{l}\text { Utility }=0.074[31] \\
\text { VAS }=7-12[32]\end{array}$ & $\begin{array}{l}\text { Validated in six countries in } \\
\text { eight patient groups with } \\
\text { chronic conditions } \\
\text { (cardiovascular disease, } \\
\text { respiratory disease, } \\
\text { depression, diabetes, liver } \\
\text { disease, personality disorders, } \\
\text { arthritis, and stroke) and a } \\
\text { student cohort }\end{array}$ & $\begin{array}{l}\text { 6MWD, NYHA FC, } \\
\text { haemodynamics }\end{array}$ & $\begin{array}{c}\text { Day of } \\
\text { data } \\
\text { collection }\end{array}$ \\
\hline $\begin{array}{l}\text { Minnesota Living } \\
\text { With Heart } \\
\text { Failure (MLHF) } \\
{[33,34]}\end{array}$ & $\begin{array}{c}\text { Heart } \\
\text { failure-specific }\end{array}$ & 21 & $\begin{array}{c}\text { Physical } \\
\text { Socioeconomic } \\
\text { Emotional/psychological }\end{array}$ & $\begin{array}{l}\text { Total 0-105 } \\
\text { Physical 0-40 } \\
\text { Emotional 0-25 } \\
\text { Higher scores } \\
\text { indicate worse } \\
\text { HRQoL }\end{array}$ & $\begin{array}{c}\text { Total score }=5-7 \text { points } \\
\text { [35] }\end{array}$ & $\begin{array}{c}\text { Validated by the International } \\
\text { Health-Related Quality of Life } \\
\text { Outcomes Database }\end{array}$ & $\begin{array}{c}\text { SF-36, 6MWD and } \\
\text { NYHA FC }\end{array}$ & 4 weeks \\
\hline $\begin{array}{l}\text { Living with } \\
\text { Pulmonary } \\
\text { Hypertension } \\
\text { (LPH) [36] }\end{array}$ & PH-specific & 21 & $\begin{array}{l}\text { Physical } \\
\text { Emotional }\end{array}$ & $\begin{array}{c}\text { Total 0-105 } \\
\text { Physical 0-40 } \\
\text { Emotional 0-25 } \\
\text { Higher scores } \\
\text { indicate worsening } \\
\text { HRQoL }\end{array}$ & $\begin{array}{l}\text { Total score }=7 \text { points } \\
\text { Subscales }=3 \text { points }\end{array}$ & $\begin{array}{c}\text { Validated in patients with PAH } \\
\text { using blinded data from a } \\
\text { double-blind phase III clinical } \\
\text { trial }\end{array}$ & $\begin{array}{l}\text { The physical } \\
\text { dimension } \\
\text { correlates with } \\
\text { Borg dyspnoea } \\
\text { score }\end{array}$ & 1 week \\
\hline
\end{tabular}




\begin{tabular}{|c|c|c|c|c|c|c|c|c|}
\hline PRO tool [ref.] & Type & Items & Domains & Scoring & MID" & Validation & Correlations & $\begin{array}{l}\text { Recall } \\
\text { period }\end{array}$ \\
\hline $\begin{array}{l}\text { Cambridge } \\
\text { Pulmonary } \\
\text { Hypertension } \\
\text { Outcome } \\
\text { Review } \\
\text { [CAMPHOR] } \\
\text { [37-40] }\end{array}$ & PH-specific & 65 & $\begin{array}{l}\text { Symptoms } \\
\text { Functioning } \\
\text { QoL }\end{array}$ & $\begin{array}{c}\text { Symptoms 0-25 } \\
\text { Functioning 0-30 } \\
\text { QoL 0-25 } \\
\text { Higher scores } \\
\text { indicate worsening } \\
\text { HRQoL }\end{array}$ & $\begin{array}{c}\text { Not available } \\
\text { However, the } \\
\text { CAMPHOR Utility } \\
\text { Index, a tool derived } \\
\text { from CAMPHOR to } \\
\text { enable cost utility } \\
\text { analyses has a MID of } \\
0.09\end{array}$ & $\begin{array}{c}\text { Validated in patients with PAH, } \\
\text { CTEPH and PH associated with } \\
\text { connective tissue disease and } \\
\text { heart failure } \\
\text { Developed from interviews } \\
\text { with patients with PH } \\
\text { Validated in the UK, USA, } \\
\text { Austria, Sweden, France, } \\
\text { Germany, Switzerland, } \\
\text { Australia, New Zealand and } \\
\text { Canada }\end{array}$ & $\begin{array}{c}\text { EQ-5D, SF-36, } \\
6 \mathrm{MWD}\end{array}$ & $\begin{array}{l}\text { At the } \\
\text { moment }\end{array}$ \\
\hline $\begin{array}{l}\text { Mahler } \\
\quad \text { dyspnoea } \\
\text { index }[41,42]\end{array}$ & $\begin{array}{l}\text { Respiratory } \\
\text { disease }\end{array}$ & 3 & $\begin{array}{l}\text { Dyspnoea } \\
\text { Magnitude of task } \\
\text { Magnitude of effort }\end{array}$ & $\begin{array}{l}\text { Baseline dyspnoea } \\
\text { index: } 5 \text { grades per } \\
\text { domain, } 4 \text { (no } \\
\text { impairment) to } 0 \\
\text { (very severe } \\
\text { impairment) } \\
\text { Transitional } \\
\text { dyspnoea index: } 6 \\
\text { grades per domain, } \\
-3 \text { (major } \\
\text { deterioration) to +3 } \\
\text { (major improvement) }\end{array}$ & 1 unit & $\begin{array}{c}\text { Validated in PAH, CTEPH, } \\
\text { COPD and interstitial lung } \\
\text { disease }\end{array}$ & $\begin{array}{l}\text { Dyspnoea diary } \\
\text { score; symptom } \\
\text { and activity } \\
\text { domains of SGRQ }\end{array}$ & $\begin{array}{l}\text { During the } \\
\text { past } \\
2 \text { weeks }\end{array}$ \\
\hline $\begin{array}{l}\text { Borg CR10 } \\
\text { dyspnoea } \\
\text { score }[43,44]\end{array}$ & $\begin{array}{l}\text { Respiratory } \\
\text { disease }\end{array}$ & 1 & Dyspnoea & $\begin{array}{l}\text { 12-unit scale from } 0 \\
\text { (nothing at all) to } 10 \\
\text { (maximal) or } 10 \text { plus } \\
\text { maximal }\end{array}$ & 1 unit & $\begin{array}{l}\text { Validated in PAH, CTEPH, heart } \\
\text { failure, COPD and other } \\
\text { respiratory diseases }\end{array}$ & $\begin{array}{l}\text { The physical } \\
\text { dimension of the } \\
\text { LPH questionnaire }\end{array}$ & $\begin{array}{c}\text { The past } \\
24 \mathrm{~h}\end{array}$ \\
\hline \multicolumn{9}{|c|}{$\begin{array}{l}\text { MOS: Medical Outcomes Study; MID: minimally important difference; PAH: pulmonary arterial hypertension; IQOLA: International Quality of Life Assessment; } 6 \text { MWD: 6-min walking } \\
\text { distance; NYHA: New York Heart Association; FC: functional class; COPD: chronic obstructive pulmonary disease; HRQLL: health-related quality of life; PH: pulmonary hypertension; QoL } \\
\text { quality of life; SGRQ: St George's Respiratory Questionnaire. "\#: MID is the smallest change or improvement that would justify an alteration in a patient's management and/or indicate a } \\
\text { clinically significant improvement. }\end{array}$} \\
\hline
\end{tabular}


medical therapies [45, 46], and in QoL studies of patients undergoing surgery or exercise training [47-50]. The EQ-5D/EQ-VAS has been used in randomised controlled trials in patients with CTEPH [51].

The HRQoL instrument Minnesota Living with Heart Failure (MLHF) survey was developed and validated in a large cohort of patients with heart failure and has been used in one open-label CTEPH study [52]. The Living with Pulmonary Hypertension (LPH) survey is an adaptation of the MLHF survey that was validated in patients with PAH [36]. It has also been used in two studies of patients with CTEPH [46, 51]. The Cambridge Pulmonary Hypertension Outcome Review (CAMPHOR) was specifically developed for patients with $\mathrm{PH}$, and when used has demonstrated sensitivity to changes in HRQoL in studies of patients with CTEPH or PAH [21,53-56]. CAMPHOR may also have use as a prognostic tool. In a retrospective analysis of CAMPHOR scores collected over 8 years in 112 patients with CTEPH and 87 with idiopathic $\mathrm{PAH}, \mathrm{CAMPHOR}$ total score and subscale scores at baseline were independent predictors of clinical deterioration [21]. This is the first time that this additional utility has been shown for a HRQoL measure in patients with $\mathrm{PH}$.

The emPHasis-10 short questionnaire has been developed for assessing HRQoL in patients with PAH and CTEPH. When tested in 226 patients with PH, of whom 82\% had PAH and 16\% had CTEPH, it showed excellent measurement properties and construct validity, and was sensitive to differences in clinical parameters [57].

In addition to QoL tools that cover multiple aspects of the patient's life, specific unidimensional PRO tools that measure dyspnoea, such as the Mahler dyspnoea index and the Borg CR10 dyspnoea score, are often used alongside other QoL/HRQoL tools. As breathlessness directly impacts on HRQoL, measures of dyspnoea are essential in $\mathrm{PH}$. The Borg dyspnoea score, which measures shortness of breath on a 12-point scale, has been used in parallel with other QoL/HRQoL tools in several clinical trials $[45,51,52,58]$. By contrast, the Mahler dyspnoea index has a stronger HRQoL component when compared with the Borg score and has been validated in several lung disease studies, but it has only been used in one trial in CTEPH [59].

An important aspect of the use of QoL tools is to establish the minimally important difference (MID). The MID is defined as the smallest difference in score for the outcome of interest that informed patients perceive as important, either beneficial or harmful, and which would lead the patient or clinician to consider a change in the patient's management [60]. MIDs are calculated statistically for individual tools, and can be used to determine if a patient has experienced an important change to their QoL as a result of treatment. The MID can also be important for calculating sample size for clinical trials [61].

As CTEPH is a globally occurring disease that remains underdiagnosed, it is important that any PRO is appropriately validated for the intended population. Most PROs are developed in English-speaking countries, and have to be accurately translated linguistically and culturally before use in other countries or populations that do not have English as their first language. Cultural adaptation ensures that the questions asked are equivalent in conceptual and semantic terms as well as linguistically [62]. One of the major challenges of validation and cultural adaptation is cost. Although the original tool may be freely available, translated and adapted versions may incur a licence fee. Therefore proprietary tools, such as CAMPHOR, may have limited applications outside large trials due to costs related to validation of new language translations and cultural adaptation.

\section{Effects of treatment on QoL in patients with CTEPH}

Surgery

The recommendations for the treatment of CTEPH from the CTEPH Working Group at the Fifth World Symposium on Pulmonary Hypertension emphasise that, in patients who are eligible for surgery, PEA is the definitive treatment for CTEPH as it is potentially curative [7]. Indeed, results from the international CTEPH registry show that PEA is associated with markedly better long-term survival than medical treatment alone, with 3-year survival rates of $89 \%$ for operated patients versus $71 \%$ for non-operated patients [63].

In addition to improved survival, several studies have shown that patients undergoing PEA have improved QoL following surgery. In a prospective study of QoL in 13 patients with CTEPH both before and 8 months after PEA, statistically and clinically significant improvements were seen in all domains of the generic MOS SF-36 questionnaire except the mental health domain (figure 1) [48]. Similarly, in a retrospective study comparing the QoL scores of 308 patients with post-operative CTEPH with those of 39 patients with pre-operative CTEPH, significant improvements were observed in all domains (physical, limits physical, limits emotional, social, energy and general health $\mathrm{p}<0.0001$; and pain $\mathrm{p}<0.01$ ) of the SF-36 questionnaire except emotional [47]. In the PEACOG study, which compared the impact of deep hypothermic circulatory arrest versus antegrade cerebral perfusion during PEA on cognitive function in 


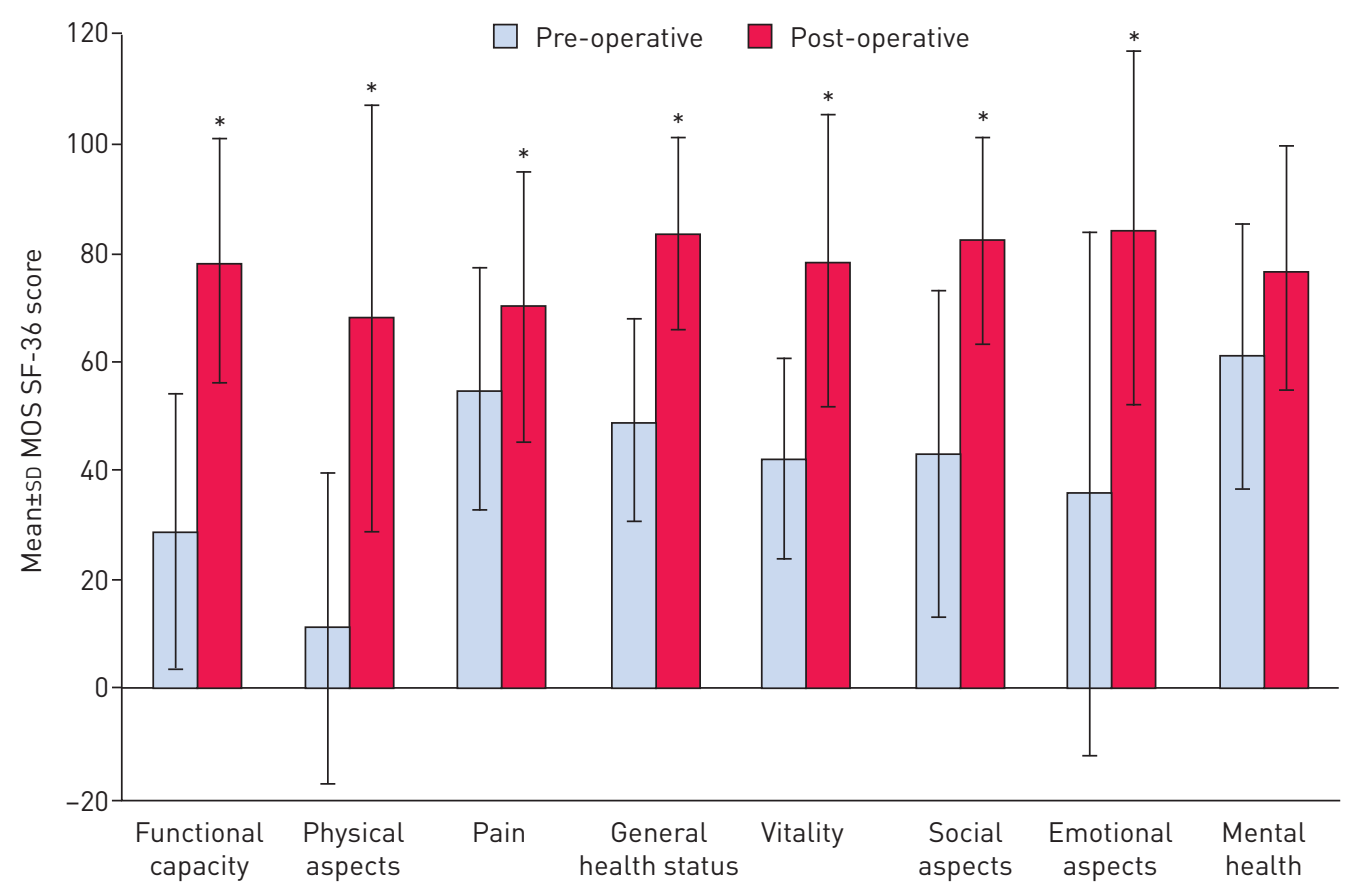

FIGURE 1 Change in domain scores of the Medical Outcomes Study (MOS) 36-item Short-Form Health Survey (SF-36) prior to and 8 months post-pulmonary endarterectomy ( $n=13)$. *: $p<0.05$. Information from [48].

74 patients with CTEPH, HRQoL scores (measured with CAMPHOR) were improved in all patients, with no difference between the deep hypothermic circulatory arrest and antegrade cerebral perfusion groups at either 12 or 52 weeks [64].

A retrospective comparison of 82 surgically and medically treated patients with CTEPH found that those receiving $\mathrm{PAH}$-targeted therapies not licenced for $\mathrm{CTEPH}$ and patients with persistent/recurrent $\mathrm{PH}$ after PEA did not have significantly improved HRQoL (measured with CAMPHOR), despite improved exercise capacity, WHO FC and Borg dyspnoea score [56]. However, patients who had undergone PEA and were left with no residual PH had significantly improved HRQoL scores in all three CAMPHOR domains $(\mathrm{p}<0.001)$. In another retrospective analysis, comparing medical and surgical treatment of 83 patients with CTEPH and distal disease, those undergoing PEA showed significant improvements in the physical functioning $(\mathrm{p}<0.01)$, role function ( $\mathrm{physical})(\mathrm{p}<0.05)$, vitality $(\mathrm{p}<0.05)$, social function $(\mathrm{p}<0.05)$ and mental health $(p<0.01)$ domains of the MOS SF-36 questionnaire following surgery, despite residual CTEPH after PEA due to distal occlusions [50]. By comparison, non-operated, medically treated patients showed significant improvement in only two domains: role function (physical) and vitality $(\mathrm{p}<0.05)$. Furthermore, surgically treated patients had statistically and clinically significantly greater improvements compared with medically treated patients in physical functioning (27.0 24.9 versus $2.7 \pm 18.0$, respectively; $\mathrm{p}<0.01)$, role function (physical) $(60.0 \pm 44.4$ versus $20.8 \pm 32.4$, respectively; $\mathrm{p}<0.05)$ and general health perception $(20.2 \pm 26.0$ versus $-3.6 \pm 13.3$, respectively; $\mathrm{p}<0.01)$ [50]. At follow-up, there were significant correlations between the physical functioning domain $(\mathrm{r}=-0.88 ; \mathrm{p}<0.01)$ and general health perception domain $(\mathrm{r}=-0.75 ; \mathrm{p}<0.01)$ of the SF-36 questionnaire and post-operative PVR, and six of the SF-36 scores significantly correlated with a percentage decrease in PVR [50].

PEA has also been shown to improve the HRQoL of patients with chronic thromboembolic disease, which is characterised by persistent pulmonary thromboembolic occlusions without PH. A small, retrospective study of symptoms and HRQoL in 16 patients who underwent PEA showed significant improvement in the symptoms, activity and QoL domains of the PH-specific CAMPHOR questionnaire at 6 months post-PEA (median total score decreased from 40 at baseline to 11 at 6 months, symptoms score from 15 to four, activity score from 10 to five and QoL score from 14 to two; $\mathrm{p}<0.05$ ). At 12 months, the scores were 11, five, four and one, respectively. These improvements were accompanied by significant improvements in exercise capacity and haemodynamics [65].

Percutaneous balloon pulmonary angioplasty (BPA) is an emerging technique that has shown improvements in pulmonary haemodynamics in patients with inoperable CTEPH or residual PH after PEA $[66,67]$. No studies have examined the effect of BPA on QoL, to date, although one study speculated 
that as patients who receive BPA could be tapered off intravenous epoprostenol, an improvement in their QoL could be expected [68].

\section{Exercise training}

There is some evidence that exercise training can improve the QoL of patients with $\mathrm{PH}[49,69]$. A prospective study of 183 patients with mixed types of $\mathrm{PH}$, including CTEPH $(n=31)$, showed that 3 weeks of in-hospital exercise training followed by 15 weeks of continued training at home led to significant improvements, even in those with severe disease, in the physical functioning $(\mathrm{p}<0.001)$, role physical $(\mathrm{p}=0.001)$, role emotional $(\mathrm{p}=0.005)$, social functioning $(\mathrm{p}=0.037)$, mental health $(\mathrm{p}=0.006)$ and vitality $(\mathrm{p}=0.002)$ subscales of the SF-36 questionnaire. These improvements were accompanied by significant improvements in exercise capacity, WHO FC, peak oxygen consumption, oxygen pulse, heart rate and systolic pulmonary artery pressure. Borg dyspnoea scores remained unchanged, despite patients achieving significantly higher workloads and heart rates during exercise [49].

\section{Medical therapy}

Although PEA is the gold standard treatment for patients with CTEPH, some patients are either inoperable or have residual CTEPH after PEA. These patients are potential candidates for medical therapy, but results have been inconsistent regarding the influence of pharmacotherapy on HRQoL. There have been very few placebo-controlled randomised phase III trials undertaken in CTEPH, to date. Generally they have been underpowered to assess QoL, which is usually measured as a secondary or exploratory end-point, with no consistency in the tools used and detailed data rarely published. Short-term trial data are limited by the fact that the benefits and side effects associated with therapy may change over time, therefore a sustained response in QoL is an important aspect of overall response to therapy. Furthermore, patient satisfaction with $\mathrm{PH}$-specific therapies may vary by treatment type and may also influence QoL [70]. To date, CHEST-2 (described later in this review) represents the only phase III clinical trial gathering long-term QoL/HRQoL data in patients with CTEPH. All of the QoL/HRQoL data published so far from clinical trials of patients with CTEPH or from trials with a mixed cohort of patients with $\mathrm{PH}$ including CTEPH are summarised in the following section and in table 2.

\begin{tabular}{|c|c|c|c|c|c|c|c|c|}
\hline $\begin{array}{l}\text { Trial name } \\
\text { (acronym) [ref.] }\end{array}$ & Treatment & Trial design & $\begin{array}{l}\text { Number/type } \\
\text { of patients }\end{array}$ & $\begin{array}{l}\text { Primary } \\
\text { end-point }\end{array}$ & $\begin{array}{c}\text { Primary } \\
\text { end-point met? }\end{array}$ & $\begin{array}{l}\text { QoL/HRQoL } \\
\text { tools used }\end{array}$ & $\begin{array}{l}\text { QoL/HRQoL } \\
\text { results }\end{array}$ & $\begin{array}{l}\text { Correlation } \\
\text { with other } \\
\text { end-points }\end{array}$ \\
\hline $\begin{array}{l}\text { Bosentan effects in } \\
\text { inoperable forms } \\
\text { of CTEPH } \\
\text { (BENEFiT) [45] }\end{array}$ & $\begin{array}{c}\text { Bosentan } \\
62.5 \mathrm{mg} \text { twice } \\
\text { daily up to } \\
125 \mathrm{mg} \text { twice } \\
\text { daily }\end{array}$ & $\begin{array}{l}\text { Multicentre, } \\
\text { randomised, } \\
\text { double-blind, } \\
\text { placebo-controlled }\end{array}$ & 157/CTEPH & $\begin{array}{c}\text { Change in PVR or } \\
6 \mathrm{MWD} \text { after } \\
16 \text { weeks of } \\
\text { treatment } \\
\text { compared with } \\
\text { placebo }\end{array}$ & $\begin{array}{l}\text { PVR end-point } \\
\text { met, but not } \\
\text { 6MWD }\end{array}$ & SF-36 & $\begin{array}{l}\text { No significant } \\
\text { difference } \\
\text { between } \\
\text { bosentan and } \\
\text { placebo groups }\end{array}$ & $\begin{array}{l}\text { None } \\
\text { performed }\end{array}$ \\
\hline $\begin{array}{l}\text { Long-term use of } \\
\text { sildenafil in } \\
\text { inoperable } \\
\text { CTEPH [58] }\end{array}$ & $\begin{array}{l}\text { Sildenafil } 40 \mathrm{mg} \\
\text { three times daily }\end{array}$ & $\begin{array}{c}\text { Randomised, } \\
\text { double-blind, } \\
\text { placebo-controlled }\end{array}$ & 19/СТЕРН & $\begin{array}{l}\text { Change in 6MWD } \\
\text { after } 12 \text { weeks of } \\
\text { treatment } \\
\text { compared with } \\
\text { placebo }\end{array}$ & No & CAMPHOR & $\begin{array}{l}\text { Significant } \\
\text { improvement } \\
\text { in the activity } \\
\text { component }\end{array}$ & $\begin{array}{c}\text { None } \\
\text { performed }\end{array}$ \\
\hline
\end{tabular}

HRQoL: health-related quality of life; PVR: pulmonary vascular resistance; 6MWD: 6-min walking distance; SF-36: 36-item Short-Form Health Survey; CAMPHOR: Cambridge Pulmonary Hypertension Outcome Review; EQ-5D: EuroQol-5D; LPH: Living with Pulmonary Hypertension. 
Pivotal trials in CTEPH

Chronic thromboembolic pulmonary hypertension soluble guanylate cyclase-stimulator trial 1

(CHEST-1)

CHEST-1 was a 16-week, multicentre, double-blind, randomised, placebo-controlled phase III trial designed to investigate the efficacy and safety of riociguat, a soluble guanylate cyclase stimulator, in 261 patients with inoperable CTEPH or persistent/recurrent PH after PEA [51]. The primary end-point of CHEST-1 was the change from baseline to the end of week 16 in 6-min walking distance (6MWD); secondary outcomes included changes in PVR, N-terminal pro-brain natriuretic peptide (NT-proBNP), WHO FC, time to clinical worsening, Borg dyspnoea score and QoL scores (the generic EQ-5D survey and the PAH-specific LPH questionnaire). In CHEST-1, a hierarchical testing procedure was performed for the secondary efficacy variables, in strict order. If, for a given variable, significance was not reached, the variables that followed were to be considered exploratory only. As EQ-5D score, Borg dyspnoea score and LPH score came after time to clinical worsening (which did not reach statistical significance) in the hierarchy these analyses can only be considered exploratory and nominally significant.

Treatment with riociguat significantly improved 6MWD compared with placebo at week 16. Significant improvements were also seen in PVR, NT-proBNP and WHO FC. In addition to these improvements, treatment with riociguat led to a placebo-corrected change in EQ-5D score by a least-squares mean difference of 0.13 (95\% CI $0.06-0.21 ; \mathrm{p}<0.0001 ; \mathrm{n}=259)$ and the EQ-VAS score by an least-squares mean difference of 10.0 (95\% CI 5.4-14.7; $\mathrm{p}<0.0001 ; \mathrm{n}=260$ ) [51], both changes exceeding the MID for the measure [71]. Although the improvement in LPH total score (the sum of all 21 items in the questionnaire) was numerically greater in the riociguat group, there was no significant difference compared with placebo (least-squares mean difference of $-6(95 \%$ CI $-10--1) ; p=0.1 ; n=256)$ [51]. A responder analysis of the LPH data, based on the MID, showed that the proportion of patients with improved/stabilised/worsened $\mathrm{LPH}$ at week 16 was $55 / 29 / 16 \%$ in the riociguat group versus $51 / 27 / 22 \%$ in the placebo group ( $\mathrm{p}=0.4997$; $\mathrm{n}=238$ ) [71]. However, as LPH was primarily validated in patients with $\mathrm{PAH}$, it is possible that further adaptation and validation may be required for use in patients with CTEPH. Borg dyspnoea score decreased in the riociguat group and increased in the placebo group $(-0.8 \pm 2$ versus $0.2 \pm 2.4$; stratified Wilcoxon test $\mathrm{p}=0.004$, nominal significance; $n=261$ ), suggesting reduction in dyspnoea in the treatment arm [51].

\section{CHEST-2 long-term extension study}

Patients who completed CHEST-1 without any ongoing study drug-related serious adverse events were eligible to enter the long-term, open-label extension study, CHEST-2 [72]. The EQ-5D and EQ-VAS were assessed at week 8 of CHEST-2, at week 12 and every 3 months thereafter. LPH was assessed at week 8 of CHEST-2.

Improvements in 6MWD and WHO FC observed in CHEST-1 persisted up to year 1 in CHEST-2. At week 12 of CHEST-2, the EQ-5D scores had improved compared with CHEST- 1 baseline by $0.13 \pm 0.24$ in the former riociguat group $(n=146)$ and by $0.07 \pm 0.23$ in the former placebo group $(n=75)$. The improvement in LPH score at week 8 was $-13.2 \pm 16.7$ in former riociguat patients $(\mathrm{n}=138)$ and $-10.8 \pm 18.9$ in former placebo patients $(n=67)$. At year 1 , the EQ-5D score compared with CHEST-1 baseline was $0.12 \pm 0.29$ in former riociguat patients $(n=113)$, a greater improvement than that seen in former placebo patients $(0.01 \pm 0.30 ; n=58)$ [72]. At year 2, patients who showed an improvement of at least $40 \mathrm{~m}$ in 6MWD saw an increase in the EQ-5D score of 0.1 (95\% CI 0.037-0.164) [73].

Observed improvements in Borg dyspnoea score for the former riociguat patients during CHEST-1 were maintained in CHEST-2 at week 12 and year 1. Upon switching to riociguat, former placebo patients showed improved Borg dyspnoea score at week 12 and year 1. The change from CHEST-1 baseline for all patients $(\mathrm{n}=171)$ at year 1 for Borg dyspnoea score was $-0.72 \pm 2.27$ [72].

\section{Bosentan effects in inoperable forms of chronic thromboembolic pulmonary hypertension (BENEFIT)}

The BENEFiT study was a 16-week, double-blind, randomised, placebo-controlled phase III study of the effect of bosentan, a dual endothelin receptor antagonist, in 157 patients with either inoperable CTEPH or persistent/recurrent CTEPH after PEA [45]. The independent co-primary end-points were change from baseline at week 16 in PVR and 6MWD. Secondary end-points included change from baseline to week 16 in WHO FC, cardiac index, total pulmonary resistance, mean right atrial pressure, mean pulmonary arterial pressure, mixed venous oxygen saturation at rest and time to clinical worsening. PROs measured at week 16 using the SF-36 and Borg dyspnoea score were exploratory end-points.

At week 16, bosentan significantly improved PVR, total pulmonary resistance and cardiac index compared with placebo. However, there was no significant improvement in $6 \mathrm{MWD}$, and the trial did not meet its 
primary end-point. There was no significant difference between the bosentan group and the placebo group QoL scores measured using the SF-36 questionnaire, although Borg dyspnoea score was significantly improved with bosentan (placebo-corrected treatment effect: -0.6 (95\% CI: $-1.2-0.0$ ); $\mathrm{p}=0.0386$ ).

\section{Pivotal trials: studies including PAH and CTEPH subgroups}

The Aerosolized Iloprost Randomized (AIR) study [46] was a 12-week, phase III, randomised, blinded, placebo-controlled trial of the prostanoid iloprost, in an aerosolised format for inhalation, in 203 patients with severe $\mathrm{PH}$ of mixed classification, including 33 patients with CTEPH. The primary end-point consisted of an increase of $\geqslant 10 \%$ in $6 \mathrm{MWD}$ and an improvement in the New York Heart Association (NYHA) FC in the absence of a clinical deterioration or death at week 12. Secondary end-points included changes in 6MWD, NYHA FC, Mahler dyspnoea index, haemodynamic variables and QoL scores (EQ-5D and SF-12).

There was a significant effect in favour of iloprost, with $16 \%$ of patients who received iloprost meeting the primary combined end-point at week 12 , compared with $5 \%$ of patients who received placebo $(\mathrm{p}=0.007)$. Although QoL was significantly improved on the EQ-VAS in the iloprost group (from $46.9 \pm 15.9$ at baseline to $52.8 \pm 19.1$ at week 12 ) compared with that of the placebo group (from $48.6 \pm 16.9$ at baseline to $47.4 \pm 21.1$ at week $12 ; \mathrm{p}=0.026$ by ANCOVA), the change did not exceed the MID for EQ-VAS [32]. There were also no significant changes in EQ-5D health state, despite it being part of the same QoL instrument as the EQ-VAS, or SF-12 score. Dyspnoea at week 12, as measured using the Mahler dyspnoea index, was significantly improved in the iloprost group compared with the placebo group (change $1.42 \pm 2.59$ versus $0.30 \pm 2.45 ; \mathrm{p}=0.015)$.

\section{Smaller pilot studies}

The BOCTEPH open-label study [52] investigated the efficacy of bosentan in 15 patients either awaiting PEA or with inoperable CTEPH, six $(40 \%)$ of whom were also receiving inhaled iloprost. The primary end-point was change in PVR at month 6. Secondary end-points included change in WHO FC, 6MWD, Borg dyspnoea score, MLHF score and haemodynamics. At month 6, significant improvements were seen in PVR and 6MWD. These improvements were accompanied by significant improvements in the MLHF physical and emotional subscores (from $25 \pm 5$ to $17 \pm 7(\mathrm{p}=0.005)$ and from $11 \pm 6$ to $6 \pm 5(\mathrm{p}=0.011$ ), respectively) and a clinically relevant reduction in the MLHF total score (from $48 \pm 14$ to $35 \pm 17 ; \mathrm{p}=0.003$ ). Borg dyspnoea scores remained unchanged at the end of the study.

The effect of treatment with the phosphodiesterase-5 inhibitor sildenafil on 19 patients with inoperable CTEPH was investigated in a 12-week, double-blind, placebo-controlled pilot study [58]. The primary end-point was change in 6MWD from baseline at week 12. Secondary end-points included changes in WHO FC, haemodynamics, NT-proBNP and CAMPHOR score. Treatment with sildenafil at week 12 led to improved haemodynamics, WHO FC and NT-proBNP levels; however, there was no significant improvement in 6MWD. At week 12, one domain of CAMPHOR, the activity domain, had improved by -2.9 (from a baseline score of $13.4(95 \%$ CI $-4.7--1.0) ; \mathrm{p}=0.008 ; \mathrm{n}=9$ ), but there was no significant change from baseline in the other two domains. Moreover, there was no significant difference in change from baseline between the sildenafil and placebo groups at week 12. Borg dyspnoea scores also did not change significantly. Patients were transferred to open-label sildenafil at week 12 , and at year 1 , the symptoms domain had improved by -2.6 (from a baseline score of 66 (95\% CI $-4.7--0.5$ ); $\mathrm{p}=0.019$ ) and the activity domain had improved by -3.3 (95\% CI $-6.0--0.6 ; \mathrm{p}=0.02)(\mathrm{n}=17)$. However, as noted in table 1, the clinical relevance of these changes remains unknown as the MIDs for individual domains of the CAMPHOR have yet to be reported. However, the CAMPHOR utility index, a tool derived from CAMPHOR to enable cost utility analyses, has a MID of 0.09 [37]. Regardless, these improvements were accompanied by significant improvements in 6MWD, cardiac index, PVR and NT-proBNP compared with baseline, but there was no significant change in Borg dyspnoea score [58].

\section{Future QoL tools for use in patients with CTEPH}

The currently available QoL tools still need to be adequately validated in patients with CTEPH and further developments are required to produce the optimum tool for clinical practice, but ideally an appropriate tool will fulfil the following criteria: 1) addresses all disease-relevant concepts; 2) addresses all issues of importance to patients; 3) sufficiently sensitive/precise to detect changes in QoL; 4) relevant across different patient groups/stratifications; 5) produces reproducible results; and 6) demonstrates unique utility in the overall assessment of patients.

More recently, new tools have been developed to measure HRQoL that may be useful in CTEPH, but these tools require further validation. The National Institutes of Health Patient-Reported Outcomes Measurement Information System (PROMIS) tool [74] is a generic QoL measure as yet untested in patients with PH. It 
aims to offer the potential for a PRO measurement that is efficient, flexible and precise. The first wave of testing, conducted in the US general population and clinical groups, has shown promising results [74]. The emPHasis-10 HRQoL measure has been specifically developed for patients with $\mathrm{PH}$, and validated in patients with $\mathrm{PAH}$; however, it is not currently recommended for use in CTEPH, as it has not been validated in this patient population [57]. Ethnography has also proved to be a valuable tool to study the QoL of patients with $\mathrm{PH}$, providing qualitative data that highlight aspects of a patient's everyday life that existing scoring questionnaires may not identify [5]; however, it would be impractical as a tool to be used regularly as part of a clinical trial or in daily practice.

\section{Conclusions}

QoL is substantially reduced in patients with CTEPH compared with the healthy population. Improvement in QoL is an outcome that can be very important to patients, rather than the change in clinical variables measured in trials such as haemodynamic parameters, which are mostly invisible to them. The advent of new treatments for inoperable or persistent/recurrent CTEPH, coupled with the increasing life expectancy of such patients means that clinicians are starting to place a greater emphasis on QoL assessment in their patients. Furthermore, among clinicians and policy makers, there is an increasing awareness of the importance of QoL data to inform decisions on patient management and policies such as drug approval and provision [75]. As a consequence, QoL questionnaires are now often used as a secondary end-point measure in clinical trials, offering another valuable indicator of the efficacy of a therapy. Indeed, several different QoL measures are available and have been used in clinical trials in patients with CTEPH. Generic tools are widely used and have an advantage over disease-specific tools, in that physicians are more familiar with generic measures and are better able to interpret results. Moreover, comparisons across disease states in which generic measures are used can facilitate understanding of the similarities and differences between disease groups [76]. The limitation of this, however, is that trials are often underpowered for the use of generic tools, and this can cause problems with the assessment of QoL. The optimal tool for assessing QoL has not been identified and aside from CAMPHOR, many of the tools currently used have not been validated in patients with CTEPH, making it difficult to draw comparisons between the currently available QoL data from CTEPH clinical trials.

PEA, the recommended surgical treatment for CTEPH, significantly improves QoL. Riociguat, the only approved medical therapy for inoperable CTEPH or persistent/recurrent PH after PEA, shows nominally significant improvements in EQ-5D and EQ-VAS scores, and CHEST remains the largest study programme to investigate QoL in patients with CTEPH over the long term. Nevertheless, QoL tools are still relatively under-used in clinical trials of patients with CTEPH and in clinical practice, and existing QoL tools require further validation in CTEPH. The ongoing development of new tools may go some way to addressing the unmet needs of QoL assessment in this disease.

\section{Acknowledgements}

Editorial assistance was provided by Adelphi Communications Ltd (Bollington, UK), supported by Bayer Pharma AG (Berlin, Germany).

\section{References}

1 Simonneau G, Robbins IM, Beghetti M, et al. Updated clinical classification of pulmonary hypertension. J Am Coll Cardiol 2009; 54: Suppl., S43-S54.

2 Delcroix M, Vonk Noordegraaf A, Fadel E, et al. Vascular and right ventricular remodelling in chronic thromboembolic pulmonary hypertension. Eur Respir J 2013; 41: 224-232.

3 Lang IM, Pesavento R, Bonderman D, et al. Risk factors and basic mechanisms of chronic thromboembolic pulmonary hypertension: a current understanding. Eur Respir J 2013; 41: 462-468.

4 Riedel M, Stanek V, Widimsky J, et al. Longterm follow-up of patients with pulmonary thromboembolism. Late prognosis and evolution of hemodynamic and respiratory data. Chest 1982; 81: 151-158.

5 Kingman M, Hinzmann B, Sweet $\mathrm{O}$, et al. Living with pulmonary hypertension: unique insights from an international ethnographic study. BMJ Open 2014; 4: e004735.

6 Galiè N, Hoeper MM, Humbert M, et al. Guidelines for the diagnosis and treatment of pulmonary hypertension. Eur Respir J 2009; 34: 1219-1263.

7 Kim NH, Delcroix M, Jenkins DP, et al. Chronic thromboembolic pulmonary hypertension. J Am Coll Cardiol 2013; 62: Suppl., D92-D99.

8 Humbert M. Pulmonary arterial hypertension and chronic thromboembolic pulmonary hypertension: pathophysiology. Eur Respir Rev 2010; 19: 59-63.

9 Mayer E, Jenkins D, Lindner J, et al. Surgical management and outcome of patients with chronic thromboembolic pulmonary hypertension: results from an international prospective registry. J Thorac Cardiovasc Surg 2011; 141: 702-710.

10 Bonderman D, Skoro-Sajer N, Jakowitsch J, et al. Predictors of outcome in chronic thromboembolic pulmonary hypertension. Circulation 2007; 115: 2153-2158.

11 Condliffe R, Kiely DG, Gibbs JS, et al. Improved outcomes in medically and surgically treated chronic thromboembolic pulmonary hypertension. Am J Respir Crit Care Med 2008; 177: 1122-1127. 
12 Freed DH, Thomson BM, Berman M, et al. Survival after pulmonary thromboendarterectomy: effect of residual pulmonary hypertension. J Thorac Cardiovasc Surg 2011; 141: 383-387.

13 Tiede $\mathrm{H}$, Hinzmann B, Bawden $\mathrm{N}$, et al. Management of chronic thromboembolic pulmonary hypertension: A physician-based perception study. Eur Respir J 2012; 40: Suppl. 56, P3271.

14 Seyfarth HJ, Halank M, Wilkens H, et al. Standard PAH therapy improves long term survival in CTEPH patients. Clin Res Cardiol 2010; 99: 553-556.

15 Conole D, Scott LJ. Riociguat: first global approval. Drugs 2013; 73: 1967-1975.

16 Bayer Pharma AG. Adempas ${ }^{\circ}$ US prescribing information. http://labeling.bayerhealthcare.com/html/products/pi/ Adempas_PI.pdf Date last updated: 2013.

17 Bayer Pharma AG. Adempas ${ }^{\circ}$ Canadian prescribing information. www.bayer.ca/files/ADEMPAS-PM-EN-17Sep2013162761.pdf Date last updated: 2013.

18 Bayer Pharma AG. Adempas ${ }^{\circ}$ (riociguat tablets): EU summary of product characteristics. www.ema.europa.eu/docs/en_ GB/document_library/EPAR__Product_Information/human/002737/WC500165034.pdf Date last updated: 2014.

19 Cenedese E, Speich R, Dorschner L, et al. Measurement of quality of life in pulmonary hypertension and its significance. Eur Respir J 2006; 28: 808-815.

20 Halank M, Einsle F, Lehman S, et al. Exercise capacity affects quality of life in patients with pulmonary hypertension. Lung 2013; 191: 337-343.

21 McCabe C, Bennett M, Doughty N, et al. Patient-reported outcomes assessed by the CAMPHOR questionnaire predict clinical deterioration in idiopathic pulmonary arterial hypertension and chronic thromboembolic pulmonary hypertension. Chest 2013; 144: 522-530.

22 Roman A, Barbera JA, Castillo MJ, et al. Health-related quality of life in a national cohort of patients with pulmonary arterial hypertension or chronic thromboembolic pulmonary hypertension. Arch Bronconeumol 2013; 49: 181-188.

23 Mathai SC, Suber T, Khair RM, et al. Health-related quality of life and survival in pulmonary arterial hypertension. Ann Am Thorac Soc 2016; 13: 31-39.

24 Harzheim D, Klose H, Pinado FP, et al. Anxiety and depression disorders in patients with pulmonary arterial hypertension and chronic thromboembolic pulmonary hypertension. Respir Res 2013; 14: 104.

25 European Pulmonary Hypertension Association. The impact of pulmonary arterial hypertension (PAH) on the lives of patients and carers: results from an international survey. www.phaeurope.org/wp-content/uploads/PAH_ Survey_FINAL.pdf Date last updated: September 2012.

26 Ware JE Jr, Sherbourne CD. The MOS 36-item short-form health survey (SF-36). I. Conceptual framework and item selection. Med Care 1992; 30: 473-483.

27 Gilbert C, Brown MC, Cappelleri JC, et al. Estimating a minimally important difference in pulmonary arterial hypertension following treatment with sildenafil. Chest 2009; 135: 137-142.

28 Ware J Jr, Kosinski M, Keller SD. A 12-Item Short-Form Health Survey: construction of scales and preliminary tests of reliability and validity. Med Care 1996; 34: 220-233.

29 Jones PW, Brusselle G, Dal Negro RW, et al. Health-related quality of life in patients by COPD severity within primary care in Europe. Respir Med 2011; 105: 57-66.

30 Euroqol Group. Euroqol - a new facility for the measurement of health related quality of life. Health Policy 1990; 16: 199-208.

31 Walters SJ, Brazier JE. Comparison of the minimally important difference for two health state utility measures: EQ-5D and SF-6D. Qual Life Res 2005; 14: 1523-1532.

32 Pickard AS, Neary MP, Cella D. Estimation of minimally important differences in EQ-5D utility and VAS scores in cancer. Health Qual Life Outcomes 2007; 5: 70.

33 Rector TS, Francis GS, Cohn JN. Patients' self-assessment of their congestive heart failure. Part 1: Patient perceived dysfunction and its poor correlation with maximal exercise tests. Heart Failure 1987; Oct/Nov: 192-196.

34 Rector TS, Kubo SH, Cohn JN. Patients' self-assessment of their congestive heart failure. Part 2: Content, reliability and validity of a new measure, the Minnesota Living with Heart Failure questionaire. Heart Failure 1987; Oct/Nov: 198-209.

$35 \mathrm{Wu} \mathrm{RC}$, Thorpe $\mathrm{K}$, Ross $\mathrm{H}$, et al. Comparing administration of questionnaires via the internet to pen-and-paper in patients with heart failure: randomized controlled trial. J Med Internet Res 2009; 11: e3.

36 Bonner N, Abetz L, Meunier J, et al. Development and validation of the living with pulmonary hypertension questionnaire in pulmonary arterial hypertension patients. Health Qual Life Outcomes 2013; 11: 161.

37 Meads DM, McKenna SP, Doughty N, et al. The responsiveness and validity of the CAMPHOR Utility Index. Eur Respir J 2008; 32: 1513-1519.

38 McKenna SP, Doughty N, Meads DM, et al. The Cambridge Pulmonary Hypertension Outcome Review (CAMPHOR): a measure of health-related quality of life and quality of life for patients with pulmonary hypertension. Qual Life Res 2006; 15: 103-115.

39 McKenna SP, Ratcliffe J, Meads DM, et al. Development and validation of a preference based measure derived from the Cambridge Pulmonary Hypertension Outcome Review (CAMPHOR) for use in cost utility analyses. Health Qual Life Outcomes 2008; 6: 65.

40 Gomberg-Maitland M, Thenappan T, Rizvi K, et al. United States validation of the Cambridge Pulmonary Hypertension Outcome Review (CAMPHOR). J Heart Lung Transplant 2008; 27: 124-130.

41 Mahler DA, Weinberg DH, Wells CK, et al. The measurement of dyspnea. Contents, interobserver agreement, and physiologic correlates of two new clinical indexes. Chest 1984; 85: 751-758.

42 Witek TJ Jr, Mahler DA. Minimal important difference of the transition dyspnoea index in a multinational clinical trial. Eur Respir J 2003; 21: 267-272.

43 Borg GA. Psychophysical bases of perceived exertion. Med Sci Sports Exerc 1982; 14: 377-381.

44 Ries AL. Minimally clinically important difference for the UCSD Shortness of Breath Questionnaire, Borg Scale, and Visual Analog Scale. COPD 2005; 2: 105-110.

45 Jaïs X, D'Armini AM, Jansa P, et al. Bosentan for treatment of inoperable chronic thromboembolic pulmonary hypertension: BENEFiT (bosentan effects in inoperable forms of chronic thromboembolic pulmonary hypertension), a randomized, placebo-controlled trial. J Am Coll Cardiol 2008; 52: 2127-2134.

46 Olschewski H, Simonneau G, Galiè N, et al. Inhaled iloprost for severe pulmonary hypertension. N Engl J Med 2002; 347: 322-329. 
47 Archibald CJ, Auger WR, Fedullo PF, et al. Long-term outcome after pulmonary thromboendarterectomy. Am J Respir Crit Care Med 1999; 160: 523-528.

48 Genta PR, Jatene FB, Terra-Filho M. Quality of life before and after pulmonary thromboendarterectomy: preliminary results. J Bras Pneumol 2005; 31: 48-51.

49 Grünig E, Lichtblau M, Ehlken N, et al. Safety and efficacy of exercise training in various forms of pulmonary hypertension. Eur Respir J 2012; 40: 84-92.

50 Yoshimi S, Tanabe N, Masuda M, et al. Survival and quality of life for patients with peripheral type chronic thromboembolic pulmonary hypertension. Circ J 2008; 72: 958-965.

51 Ghofrani HA, D'Armini AM, Grimminger F, et al. Riociguat for the treatment of chronic thromboembolic pulmonary hypertension. N Engl J Med 2013; 369: 319-329.

52 Ulrich S, Speich R, Domenighetti G, et al. Bosentan therapy for chronic thromboembolic pulmonary hypertension. A national open label study assessing the effect of Bosentan on haemodynamics, exercise capacity, quality of life, safety and tolerability in patients with chronic thromboembolic pulmonary hypertension (BOCTEPH-Study). Swiss Med Wkly 2007; 137: 573-580.

53 Browne E, Echevarria C, Lordan J, et al. Medical treatment of chronic thromboembolic pulmonary hypertension. Am J Crit Care Med 2010; 181: A1951.

54 Small M, Piercy J, Pike J, et al. Incremental burden of disease in patients diagnosed with pulmonary arterial hypertension receiving monotherapy and combination vasodilator therapy. Adv Ther 2014; 31: 168-179.

55 Twiss J, McKenna S, Ganderton L, et al. Psychometric performance of the CAMPHOR and SF-36 in pulmonary hypertension. BMC Pulm Med 2013; 13: 45.

56 Thakrar MV, Hall A, Crackett R, et al. Functional and quality of life improvements in treated patients with chronic thromboembolic pulmonary hypertension. J Heart Lung Transplant 2013; 32: Suppl., S304.

57 Yorke J, Corris P, Gaine S, et al. emPHasis-10: development of a health-related quality of life measure in pulmonary hypertension. Eur Respir J 2014; 43: 1106-1113.

58 Suntharalingam J, Treacy CM, Doughty NJ, et al. Long-term use of sildenafil in inoperable chronic thromboembolic pulmonary hypertension. Chest 2008; 134: 229-236.

59 Olschewski H. Inhaled iloprost for the treatment of pulmonary hypertension. Eur Respir Rev 2009; 18: 29-34.

60 Schunemann HJ, Puhan M, Goldstein R, et al. Measurement properties and interpretability of the chronic respiratory disease questionnaire (CRQ). COPD 2005; 2: 81-89.

61 Revicki D, Hays RD, Cella D, et al. Recommended methods for determining responsiveness and minimally important differences for patient-reported outcomes. J Clin Epidemiol 2008; 61: 102-109.

62 Guillemin F, Bombardier C, Beaton D. Cross-cultural adaptation of health-related quality of life measures: literature review and proposed guidelines. J Clin Epidemiol 1993; 46: 1417-1432.

63 Simonneau G, Delcroix M, Lang IM, et al. Long-term outcome of patients with chronic thromboembolic pulmonary hypertension: results of an international prospective registry comparing operated versus non operated patients. Am J Respir Crit Care Med 2013; 187: A5364.

64 Vuylsteke A, Sharples L, Charman G, et al. Circulatory arrest versus cerebral perfusion during pulmonary endarterectomy surgery (PEACOG): a randomised controlled trial. Lancet 2011; 378: 1379-1387.

65 Taboada D, Pepke-Zaba J, Jenkins DP, et al. Outcome of pulmonary endarterectomy in symptomatic chronic thromboembolic disease. Eur Respir J 2014; 44: 1635-1645.

66 Hoeper MM, Madani MM, Nakanishi N, et al. Chronic thromboembolic pulmonary hypertension. Lancet Respir Med 2014; 2: 573-582.

67 Kurzyna M, Darocha S, Koteja A, et al. Balloon pulmonary angioplasty for chronic thromboembolic pulmonary hypertension. Postepy Kardiol Interwencyjnej 2015; 11: 1-4.

68 Sugimura K, Fukumoto Y, Satoh K, et al. Percutaneous transluminal pulmonary angioplasty markedly improves pulmonary hemodynamics and long-term prognosis in patients with chronic thromboembolic pulmonary hypertension. Circ J 2012; 76: 485-488.

69 Inagaki $\mathrm{T}$, Terada J, Tanabe $\mathrm{N}$, et al. Home-based pulmonary rehabilitation in patients with inoperable or residual chronic thromboembolic pulmonary hypertension: a preliminary study. Respir Investig 2014; 52: 357-364.

70 Chen H, Rosenzweig EB, Gotzkowsky SK, et al. Treatment satisfaction is associated with improved quality of life in patients treated with inhaled treprostinil for pulmonary arterial hypertension. Health Qual Life Outcomes 2013; 11: 31 .

71 Ghofrani H-A, Grimminger F, Hoeper MM, et al. Impact of riociguat on health-related quality of life (HRQoL) in patients with chronic thromboembolic pulmonary hypertension (CTEPH). Eur Respir J 2013; 42: Suppl. 57, P3418.

72 Simonneau G, D'Armini AM, Ghofrani HA, et al. Riociguat for the treatment of chronic thromboembolic pulmonary hypertension: a long-term extension study (CHEST-2). Eur Respir J 2015; 45: 1293-1302.

73 Minai OA, Bonner N, Odufowora-Sita O, et al. Health outcome assessment in chronic thromboembolic pulmonary arterial hypertension patients treated with riociguat: 2-year results from the CHEST-2 long term extension study. Am J Respir Crit Care Med 2015; 191: A4848.

74 Cella D, Riley W, Stone A, et al. The Patient-Reported Outcomes Measurement Information System (PROMIS) developed and tested its first wave of adult self-reported health outcome item banks: 2005-2008. J Clin Epidemiol 2010; 63: 1179-1194.

75 Guyatt GH, Feeny DH, Patrick DL. Measuring health-related quality of life. Ann Intern Med 1993; 118: 622-629.

76 Fletcher A, Gore S, Jones D, et al. Quality of life measures in health care. II: Design, analysis, and interpretation. BMJ 1992; 305: 1145-1148. 